\title{
Palmitic acid up regulates Gal-3 and induces insulin resistance in macrophages by mediating the balance between KLF4 and NF-кB
}

\author{
JING LI, YU-SHAN MAO, FEN CHEN, DONG-XIA XIA and TIN-QI ZHAO \\ Department of Endocrinology and Metabolism, The Affiliated Hospital of Medical School of Ningbo University, \\ Ningbo, Zhejiang 315020, P.R. China
}

Received August 1, 2020; Accepted May 24, 2021

DOI: $10.3892 /$ etm.2021.10460

\begin{abstract}
Insulin resistance is the main sign of type 2 diabetes mellitus and is often accompanied by the infiltration of inflammatory factors. These inflammatory factors are mainly produced and secreted by macrophages. The purpose of the current study was to explore the relationship between macrophages and insulin resistance, and to determine its underlying mechanism. The insulin resistance of macrophages was induced by palmitic acid (PA) in vitro. The glucose uptake rate of macrophages, the expression levels of inflammatory cytokines and the expression levels of insulin resistance-related proteins were detected. The protein expression levels of Krüppel-like factor 4 (KLF4), toll-like receptor 4 (TLR4), NF- $\kappa$ B and Galectin-3 (Gal-3) were detected via western blotting and recovery experiments were performed by combining the Gal-3 and TLR4 inhibitors GB1107 and TAK242. The results revealed that $\mathrm{PA}$-induced macrophages demonstrated insulin resistance. Additionally, KLF4 protein was inhibited and the sugar uptake rate was significantly lower than that of the control group. Western blotting and immunofluorescence assays revealed that the expression of Gal-3 in PA-induced macrophages was significantly upregulated. The addition of the Gal-3 inhibitor GB1107 significantly increased glucose utilization and reduced insulin resistance in PA-treated cells. Inhibitor of TLR4 inhibited the protein expression level of the TLR4/NF- $\kappa \mathrm{B}$ pathway. In conclusion, PA promoted the TLR4/phosphorylated-NF- $\kappa$ B signaling pathway by inhibiting
\end{abstract}

Correspondence to: Mrs. Jing Li, Department of Endocrinology and Metabolism, The Affiliated Hospital of Medical School of Ningbo University, 247 Renmin Road, Jiangbei, Ningbo, Zhejiang 315020, P.R. China

E-mail: fylijing@nbu.edu.cn

Abbreviations: FFA, free fatty acid; Gal-3, galectin-3; NF- $\kappa \mathrm{B}$, nuclear factor $\kappa \mathrm{B}$; PA, palmitic acid; T2DM, type 2 diabetes mellitus

Key words: Galectin-3, insulin resistance, Krüppel-like factor 4, macrophages, phosphorylated-NF- $\mathrm{B}$, palmitic acid, toll-like receptor 4
KLF4, promoted the upregulation of Gal-3 expression and improved the insulin resistance of macrophages.

\section{Introduction}

Diabetes mellitus is a common worldwide metabolic disease, and its incidence continues to increase every year. Type 2 diabetes mellitus (T2DM) accounts for $>90 \%$ of the total number of patients with diabetes; it is a glucose and fat metabolic disorder syndrome caused by insulin resistance and insufficient insulin secretion (1). T2DM has become the most prevalent chronic noncommunicable disease in the world, the main cause of which is obesity. According to the International Diabetes Federation, patients with T2DM in Asia account for $60 \%$ of cases worldwide (2). A previous study (3) also indicated that the overall prevalence of diabetes in adults is $9.1 \%$, implying that 415 million adults suffer from diabetes globally. The incidence of obesity in China has rapidly increased in recent years, exceeding $42 \%$ (4).

A number of studies have shown a significant increase in the free fatty acid (FFA) level in the blood of obese patients $(5,6)$. FFA includes palmitic acid (PA) and other fatty acids (6). The intake of a large amount of saturated fatty acids, especially PA, can cause disorders of glucose and lipid metabolism in the human body (5). Therefore, excessively high levels of FFAs in the body may be crucial in causing obesity and T2DM (7). The recruitment, infiltration and polarization of macrophages in adipose tissue serve an essential role in the occurrence of obesity (8). The inflammatory response caused by macrophages is believed to be the link between obesity and diabetes. Inflammatory factors mediate the occurrence of insulin resistance by influencing the insulin signaling pathway. For example, tumor necrosis factor $\alpha$ (TNF- $\alpha)$, the first proinflammatory cytokine found to be associated with insulin resistance, is vital in insulin resistance (9). It can interfere with the phosphorylation of insulin receptor substrate 1 (IRS-1) in adipocytes through JNK1 and damage the insulin signaling pathway, thereby causing insulin resistance (10). Proinflammatory cytokines can also downregulate the expression of IRS-1 and glucose transporter type 4, insulin-responsive (GLUT4) proteins in adipocytes and impair insulin action (11). Inflammatory factors can also reversely act on macrophages to expand the inflammation response (12). This indicates that the metabolism of macrophages is essential for insulin resistance. 
PA is widely found in nature; almost all fats and oils contain varying amounts of PA, and it is the most abundant saturated fatty acid in a high-fat diet (13). Moreover, it is important in fat metabolism in macrophages. A previous study found that PA can induce insulin resistance in liver cells through reactive oxygen species produced by mitochondria (14). In cells, PA can activate multiple Toll-like receptor (TLR)-dependent signaling pathways to increase mRNA and protein expression levels of TLR and enhance the receptor's signal transduction (13). Another study demonstrated high expression of TLR4 in proinflammatory macrophages and in differentiated adipocytes (15). The expression of TLR4 in human adipocytes increases with increasing levels of obesity and can be activated by lipopolysaccharide to induce the production of nuclear factor- $\kappa \mathrm{B}(\mathrm{NF}-\kappa \mathrm{B})$ and cytokines (16). Therefore, the present study aimed to explore whether PA-induced insulin resistance was also related to the abnormal activation of TLR4-dependent pathways and how this resistance could be regulated.

Galectin-3 (Gal-3) is a lectin that is primarily secreted by macrophages. Elevated levels of Gal-3 have been reported in obese individuals and mice (17). The administration of Gal-3 to mice can cause insulin resistance and glucose intolerance, and the inhibition of Gal-3 can improve insulin sensitivity in obese mice. Gal-3 treatment in vitro can directly enhance the chemotaxis of macrophages and reduce the uptake of glucose by insulin-stimulated muscle cells and 3T3-L1 adipocytes. Studies have also shown that Gal-3 can directly interact with the insulin receptor (IR) and inhibit downstream IR signaling $(17,18)$. These findings illustrate the vital role of Gal-3 in insulin resistance in liver, fat and muscle cells, indicating that Gal-3 can link inflammation with decreased insulin sensitivity. The inhibition of Gal-3 may serve as a new strategy to treat insulin resistance. However, the specific mechanism underlying macrophage-mediated insulin resistance is still unclear. The findings of the present study may offer insight into the mechanism underlying PA-mediated regulation of Gal-3 expression through TLR4, thus providing the basis for the establishment of related intervention methods in the future.

\section{Materials and methods}

Cell lines and reagents. Human acute monocytic leukemia cells THP-1 were purchased from The Cell Bank of Type Culture Collection of The Chinese Academy of Sciences (Shanghai, China). TRIzol ${ }^{\circledR}$ RNA extraction reagent (Invitrogen), 1st Strand cDNA Synthesis kit gDNA Purge (Novoprotein; cat. no. E042-01B), SYBR qPCR SuperMix Plus (Novoprotein; cat. no. E096-01A) and reverse transcription RT-PCR primers (Invitrogen) were from Thermo Fisher Scientific, Inc. The primers for qPCR were commissioned to be synthesized by Genewiz, Inc. Primary antibodies, including Krüppel-like factor 4 (KLF4; cat. no. R1308-1), insulin receptor (INSR; cat. no. ET1705-22), IRS1 (cat. no. ER2001-35), Gal-3 (cat. no. ER1803-82), NF-кB (cat. no. ER0815), phosphorylated ( $p$ )-NF-кB p65 (S529) antibody (cat. no. ET1604-27), TLR4 (cat. no. ER1706-43) and GAPDH (cat. no. ER1706-83), were purchased from Hangzhou Hua'an Biotechnology Co., Ltd. The $p$-IRS1 (Ser1101) primary antibody (cat. no. 2385) was from Cell Signaling Technology, Inc. The following secondary antibodies were used: Horseradish peroxidase-conjugated goat anti-rabbit IgG (cat. no. HA1001; Hangzhou HuaAn Biotechnology Co., Ltd.) and FITC-conjugated goat anti-rabbit antibody, (cat. no. HA1004; Hangzhou HuaAn Biotechnology Co., Ltd.). DAPI was purchased from Beyotime Institute of Biotechnology, and the (3R,4R,5S,6R)6-(hydroxymethyl)3-[(7-nitrobenzo(c) $(1,2,5)$ oxadiazol-4-yl) amino] tetrahydro-2H pyran-2,4,5-triol (2-NBDG) glucose uptake/transport fluorescent probe (cat. no. MX4511-1MG) was from Shanghai Mao Kang Biological Technology, Co., Ltd. The TLR4 protein inhibitor (TAK 242; cat. no. 243984-11-4) was also obtained from Merck KGaA. All protocols and the use of human peripheral blood were approved by the Affiliated Hospital of Medical School of Ningbo University (Ningbo, China; approval no. KY20190102). A total of 10 men (40-50 years old; including 5 healthy individuals and 5 patients with type 2 diabetes) and 10 women (40-50 years old; including 5 healthy individuals and 5 patients with type 2 diabetes) were admitted to the Affiliated Hospital of Ningbo University from January 2018 to December 2018 to detect the expression level of Gal-3 protein in the peripheral blood of patients. All subjects provided oral informed consent.

Induction of THP-1 cells by phorbol 12-myristate 13-acetate (PMA) to differentiate into macrophages. THP-1 cells were grown in a 6 -well plate $\left(5 \times 10^{6}\right.$ cells/well) and grown in an incubator at $37^{\circ} \mathrm{C}$ and $5 \% \mathrm{CO}_{2}$ in RPMI-1640 (cat. no. ZQ-230) medium containing 10\% FBS (cat. no. ZQ500; Zhejiang Ruyao Biotechnology Co., Ltd.). Cells between passage four to eight were selected for the experiments based on the cell growth state and cell morphology. A total of $1 \times 10^{6}$ cells/well were inoculated in a 6-well plate and grown in an incubator at $37^{\circ} \mathrm{C}$ and $5 \% \mathrm{CO}_{2}$ in RPMI-1640 medium containing $10 \% \mathrm{FBS}$. The differentiated macrophages were identified after treatment with $200 \mathrm{ng} / \mathrm{ml} 12-O-T e t r a d e c a n o y l-p h o r b o l ~ 13-A c e t a t e$ (PMA; cat. no. P6741; Beijing Solarbio Science \& Technology Co., Ltd.) for 3 days.

Identification of macrophages. A total of $2 \times 10^{6}$ cells/well were inoculated in a 24-well plate and grown in an incubator at $37^{\circ} \mathrm{C}$ and $5 \% \mathrm{CO}_{2}$ in RPMI-1640 medium containing $10 \%$ FBS for 2 h. Cultured macrophages were washed with PBS and fixed with methanol at $4^{\circ} \mathrm{C}$ for $20 \mathrm{~min}$. After fixation, all subsequent steps were carried out at room temperature. Samples were washed 1X PBS and stained with hematoxylin for $3 \mathrm{~min}$ and eosin for $5 \mathrm{sec}$. After dehydration, xylene was added and neutral gum was used for sealing. Cultured THP-1 cells that did not receive PMA induction were centrifuged at $800 \mathrm{x}$ g room at temperature for $5 \mathrm{~min}$, resuspend $100 \mu \mathrm{l}$ in $1 \mathrm{X}$ PBS and then dropped onto a slide. After air drying, the cells were fixed with methanol at $4^{\circ} \mathrm{C}$ for $20 \mathrm{~min}$, followed by HE staining using the same method as described above. Prior to HE staining, both groups of cells were photographed under a phase contrast microscope to observe their morphology (magnification, $\mathrm{x} 100$ and $\mathrm{x} 400$ ). In addition, THP-1 cells were cultured in a 24-well plate with the inoculation density of $2 \times 10^{6}$ cells per well, and used for microsphere phagocytosis test. A drop of polystyrene microspheres (cat. no. P107780; Shanghai Aladdin Biochemical Technology Co., Ltd.) was added to $2.5 \mathrm{ml}$ PBS, mixed thoroughly and then $5 \mu$ l diluted 
beads were added to the PMA-treated THP-1 cells. The cells were incubated at $37^{\circ} \mathrm{C}$ for $50 \mathrm{~min}$ and then washed twice with 1x PBS. The phagocytosed microspheres were counted under an inverted microscope (magnification, x100). Phagocytosis rate $(\%)=($ the number of phagocytic pellets/the number of cells in one field).

Induction of insulin resistance and inflammatory factors in macrophages. Macrophages in good growth condition and in the logarithmic growth phase were treated with 0, 200, 400 or $600 \mu \mathrm{M}$ PA (cat. no. P0500; Merck KGaA) for $24 \mathrm{~h}$. Subsequently, the cells were tested for glucose uptake ability according to the glucose uptake assay protocol described below. The cell supernatant was collected via centrifugation at $800 \mathrm{x} \mathrm{g}$ for $20 \mathrm{~min}$ at $4^{\circ} \mathrm{C}$ and the inflammatory factors, including interleukin (IL)-1 $\beta$ (cat. no. SEKH-0002), IL-6 (cat. no. SEKH-0013) and TNF- $\alpha$ (cat. no. SEKS-0003), were detected by ELISA (all from Beijing Solarbio Science $\&$ Technology Co., Ltd.) according to the manufacturer's protocol.

Glucose uptake assay. For the glucose uptake assay, $1 \times 10^{5}$ macrophages were used following treatment with PA $(0,200$, 400 or $600 \mu \mathrm{M})$, inoculated $\left(1 \times 10^{5}\right.$ cells/well) in a 6 -well plate, cultured at $37^{\circ} \mathrm{C}$ for $48 \mathrm{~h}$, washed three times with PBS and incubated with $100 \mu \mathrm{M} 2-\mathrm{NBDG}$ at $37^{\circ} \mathrm{C}$ for $20 \mathrm{~min}$. The cells were washed three times with precooled PBS, digested with $0.25 \%$ trypsin, collected via centrifugation at $800 \mathrm{x}$ g for $5 \mathrm{~min}$ at $4^{\circ} \mathrm{C}$ and examined using an Attune NxT flow cytometer (Thermo Fisher Scientific, Inc.) with FlowJo 10 software (FlowJo LLC).

Cell viability test. Macrophages were collected in the logarithmic growth phase and cell viability was detected using the MTT method. A total of $100 \mu 1$ macrophages were added to each well, and the density of the cells was adjusted to $5 \times 10^{3}$ macrophages/well (the edge holes were filled with sterile PBS). The cells were incubated at $37^{\circ} \mathrm{C}$ and $5 \% \mathrm{CO}_{2}$ until the macrophage monolayer covered the bottom of the well (96-well flat-bottom plate). After the adherent growth of macrophages, cells were treated with $100 \mu \mathrm{l}$ drug-containing complete medium (PA, 0, 200, 400 and $600 \mu \mathrm{M}$ ) in each well. After incubation at $37^{\circ} \mathrm{C}$ for $48 \mathrm{~h}, 20 \mu \mathrm{l} 5 \%$ MTT was added to each well for $4 \mathrm{~h}$. The culture medium in the well was removed, $150 \mu \mathrm{l}$ DMSO was added. The absorbance was measured at an optical density of $490 \mathrm{~nm}$ using a microplate reader (MultiskanGO; Thermo Fisher Scientific, Inc.).

Western blot analysis. The macrophages $\left(1 \times 10^{6}\right)$ were removed from the $\mathrm{CO}_{2}$ incubator after $24 \mathrm{~h}$ treatment with PA and washed twice with precooled PBS. The remaining PBS was aspirated, the cells were lysed with RIPA lysis buffer (cat. no. R0010; Beijing Solarbio Science \& Technology Co., Ltd.) on ice and then the macrophage lysate was pipetted to destroy the DNA. A total of $3 \mu 1$ lysate was used for BCA quantification. Further, $4 \mathrm{X}$ protein loading buffer was added to the remaining samples, incubated at $95^{\circ} \mathrm{C}$ for $10 \mathrm{~min}$ to denature and stored at $-20^{\circ} \mathrm{C}$ until further analysis. Proteins $(40 \mu \mathrm{g})$ were separated by $10 \%$ SDS-PAGE, transferred to a PVDF membrane at a constant current of $200 \mathrm{~mA}$ for $2 \mathrm{~h}$ and blocked with $5 \%$ skimmed milk for $1 \mathrm{~h}$ at room temperature. The membranes were incubated with the primary antibody (rabbit anti p-IRS1/IRS1/INSR/KLF4/Gal-3; all, 1:1,000) overnight at $4^{\circ} \mathrm{C}$. The internal reference antibody GAPDH was added and incubated for $1 \mathrm{~h}$ at room temperature (cut according to marker size). The membrane was washed three times with $1 \mathrm{X}$ TBST $(0.15 \%$ Tween-20), then incubated with the secondary antibody at room temperature for $2 \mathrm{~h}$, followed by three washes with TBST. Proteins were visualized using ECL solution (cat. no. PE0010; Beijing Solarbio Science \& Technology Co., Ltd.). The ChemiDoc-It Imaging System (UVP, LLC) was used for observation and Image J 8.0 (National Institutes of Health) was used for quantification. When assessing the protein levels of the downstream TLR4 pathway, four groups were constructed: The control group; the PA group, which received induction with $400 \mu \mathrm{m} \mathrm{PA}$; the TAK-242 group, in which macrophages were treated with $1 \mu \mathrm{M}$ TAK-242; and the TAK-242 + PA group, where macrophages were treated with $400 \mu \mathrm{M}$ PA and $1 \mu \mathrm{M}$ TAK-242. After administration, macrophages were cultured for $24 \mathrm{~h}$ under $5 \% \mathrm{CO}_{2}$ and $37^{\circ} \mathrm{C}$. Western blot analysis was performed at the end of treatment using the same procedures as described above.

$R T$-qPCR. After $24 \mathrm{~h}$ of treatment with PA, the treated macrophages were collected $\left(1 \times 10^{6}\right)$ and totalRNAwas extracted by the TRIzol ${ }^{\circledR}$ method. An ultramicro-spectrophotometer (NanoDrop One/OneC; Thermo Fisher Scientific, Inc.) was used to detect nucleic acid concentration, and the integrity of the extracted mRNA was verified by agarose gel electrophoresis. After incubating samples at $25^{\circ} \mathrm{C}$ for $5 \mathrm{~min}$, the 1 st Strand cDNA Synthesis kit (cat. no. E047-01A; Novoprotein) was applied and used according to the manufacturer's protocol, incubating samples at $42^{\circ} \mathrm{C}$ for $60 \mathrm{~min}$ for RT. The reaction was terminated by heating at $70^{\circ} \mathrm{C}$ for $5 \mathrm{~min}$, and the mRNA was reverse transcribed into cDNA. qPCR was conducted using SYBR qPCR SuperMix Plus for analysis, along with the 7500 Fast Real-Time PCR System (Applied Biosystems; Thermo Fisher Scientific, Inc.). The reaction mixture contained $20 \mathrm{ng}$ cDNA, $1.5 \mathrm{mmol}$ of each primer and $2.5 \mathrm{mM}$ $\mathrm{MgCl}_{2}$, and the thermocycling conditions were as follows: Initial denaturation at $95^{\circ} \mathrm{C}$ for $2 \mathrm{~min}$; followed by 40 cycles of denaturation at $95^{\circ} \mathrm{C}$ for $10 \mathrm{sec}$, annealing at $60^{\circ} \mathrm{C}$ for $10 \mathrm{sec}$ and extension at $72^{\circ} \mathrm{C}$ for $30 \mathrm{sec}$. The relative expression of Gal-3 was calculated using the $2^{-\Delta \Delta \mathrm{Cq}}$ method (19). Primer 3 (Premier Biosoft International.) was used to design primer pairs; the sequences were as follows: Gal-3, forward 5'-CGG AGCCAGCCAACGAG-3' and reverse, 5'-AACGCATCATGG AGCGAAAA-3'; GAPDH forward, 5'-GCACCGTCAAGG CTGAGAAC-3' and reverse, 5'-TGGTGAAGACGCCAGTGG A-3'.

Immunofluorescence. THP-1 cells $\left(1 \times 10^{6}\right)$ were inoculated on a 6-well plate with a cover glass slide placed on the plate. After inducing macrophages with PMA, the cells were then slip-fed and cultured at $37^{\circ} \mathrm{C}$ and $5 \% \mathrm{CO}_{2}$ for $24 \mathrm{~h}$ until a $70 \%$ fusion degree was reached. The next day, $400 \mu \mathrm{M}$ PA and 37 nM GB1107 (Shanghai ZrBiorise Biotechnology Co., Ltd.; cat. no. 1978336-61-6) were added, and set up the experimental group with the above two reagents, the standard medium was 
A

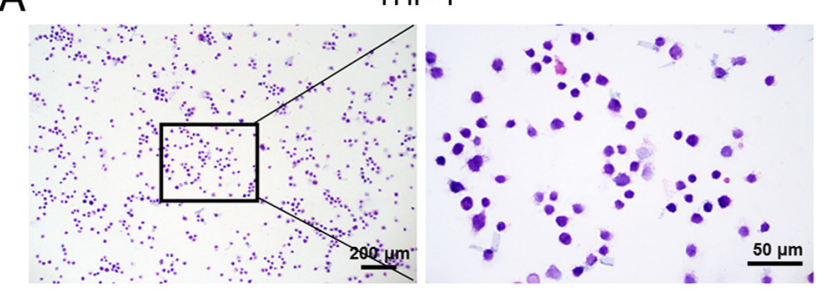

B

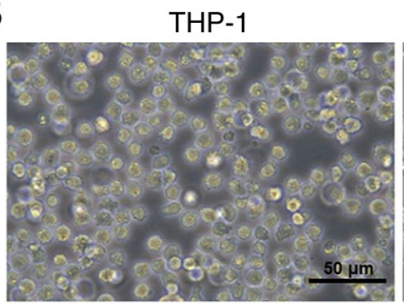

C

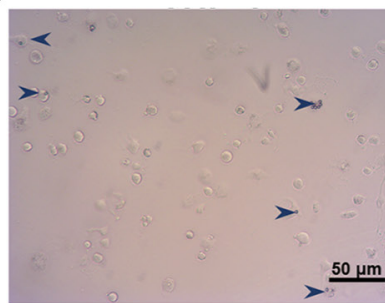

THP-1+PMA

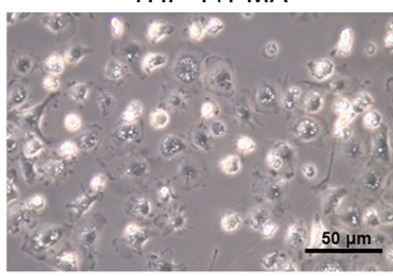

THP-1+PMA

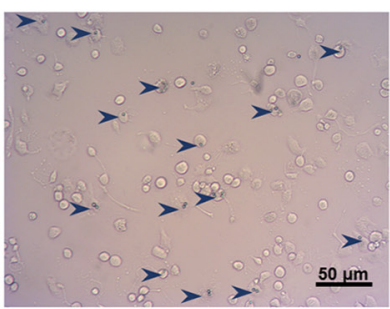

THP-1+PMA

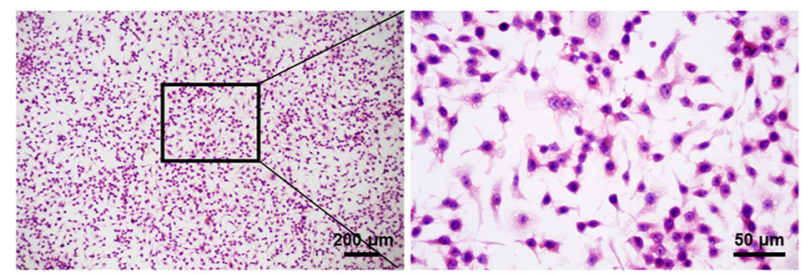

$\mathrm{D}$

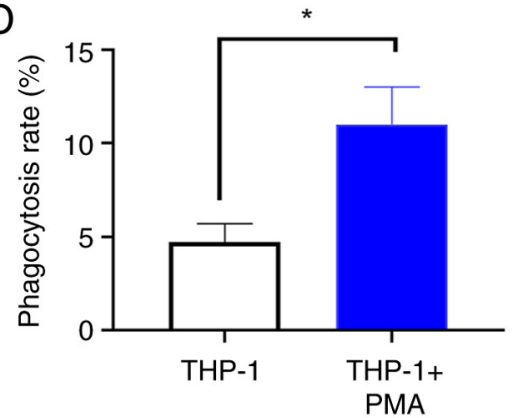

Figure 1. Induction of THP-1 differentiation into macrophages by PMA. (A) Results of hematoxylin and eosin staining. The left image of each group was obtained at a magnification of x100 (left-hand image scale bars, $200 \mu \mathrm{m}$ ). The images on right were obtained at a magnification of x400 (right-hand image scale bars $50 \mu \mathrm{m}$ ). (B) The morphology of THP-1 cells under the indicate treatments were observed under phase-contrast microscopy. (C) Images of microsphere phagocytosis assay. (D) Phagocytic rate of macrophages based on (C). PMA, phorbol 12-myristate 13-acetate. ${ }^{*} \mathrm{P}<0.05$ vs. THP-1.

used for the negative control. The groups were divided into four: The control group; the PA group, where macrophages were treated with $400 \mu \mathrm{MPA}$; the GB1107 group, where macrophages were treated with $37 \mathrm{nM} \mathrm{GB1107}$; and the PA+GB1107 group, where macrophages were treated with $400 \mu \mathrm{M}$ PA and $37 \mathrm{nM}$ GB1107. Cells were incubated for $8 \mathrm{~h}$ at $37^{\circ} \mathrm{C}$ with $5 \% \mathrm{CO}_{2}$. The cells were then fixed with $4 \%$ paraformaldehyde for $20 \mathrm{~min}$ at room temperature and incubated with rabbit antibody-3 antibodies (1:100) at room temperature for $2 \mathrm{~h}$. Cells were then incubated with the FITC-labeled secondary antibody (goat anti rabbit; 1:500). The nuclei were stained and sealed with anti-fluorescence quenching solution (including DAPI; cat. no. P0131; Beyotime Institute of Biotechnology) was added. A Leica DM500 fluorescence microscope was used to observe and obtain images (Leica Microsystems $\mathrm{GmbH}$ ). Image-Pro Plus 6.0 (Media Cybernetics, Inc.) software was used for the quantification of results.

Bioinformatics analysis. The names of all proteins were put into the string website to predict the relationship between proteins (https://string-db.org/).

Statistical analysis. All experiments were repeated three times separately, and the data are expressed as the mean \pm standard deviation, differences between two groups were measured by unpaired Student's t-test using SPSS 22.0 software (IBM Corp.). One-way ANOVA was used to analyze differences between multiple groups, followed by Tukey's post hoc test. $\mathrm{P}<0.05$ was considered to indicate a statistically significant difference.

\section{Results}

Induction of macrophage differentiation. The adherent macrophages induced by PMA were observed directly under a light microscope and phase contrast microscope after $\mathrm{HE}$ staining (Fig. 1A and B). The adherent cells exhibited clear boundaries and blunt round protrusions. The nuclei were large and irregularly shaped at one end of the cell. THP-1 cells without PMA induction demonstrated a round karyotype and less cytoplasm. In addition, the macrophages phagocytosed the microspheres, indicating that the PMA-induced THP-1 cells exhibited phagocytic ability (Fig. 1C), which was statistically significant compared with the number of phagocytosed microspheres in the uninduced THP-1 cells ( $\mathrm{P}<0.05$; Fig. 1D). The results indiacted that PMA could induce macrophage differentiation successfully.

PA induces macrophages to produce insulin resistance and promote the secretion of inflammatory factors. Macrophages were treated with $0,200,400$ or $600 \mu \mathrm{M}$ PA, and 2-NBDG was used to detect the sugar uptake ability of macrophages. The results showed that the glucose uptake was significantly lower in the PA-treated groups compared with uptake in the control group ( $\mathrm{P}<0.01$; Fig. 2A). In addition, the protein expression levels of $p$-INSR, INSR, and IRS1 were detected by western blotting. The results demonstrated that the expression levels of INSR were downregulated following PA treatment, and $p$-IRS1 was significantly decreased $(\mathrm{P}<0.05)$ (Fig. $2 \mathrm{~B}$ and $\mathrm{C}$ ), indicating that PA induced insulin resistance in macrophages. 


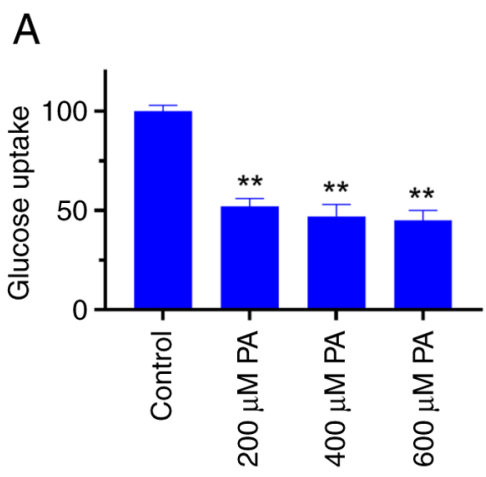

B

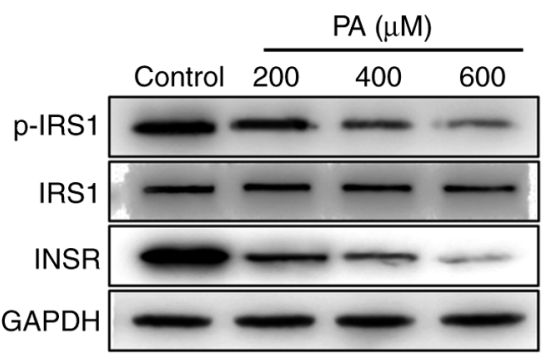

C

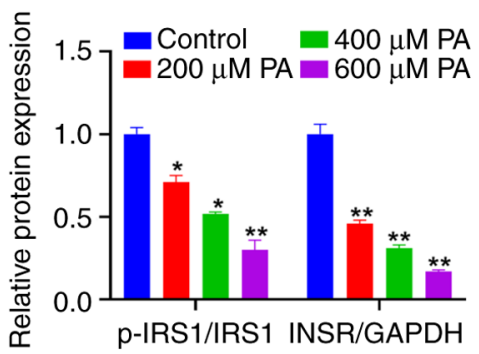

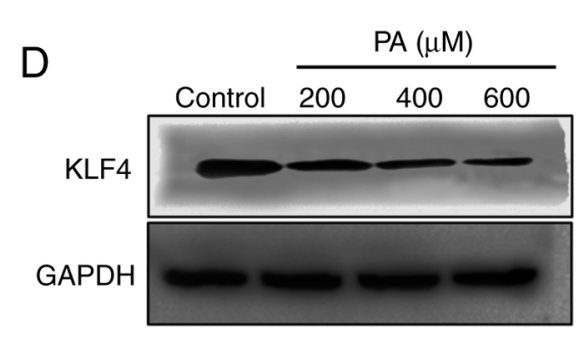
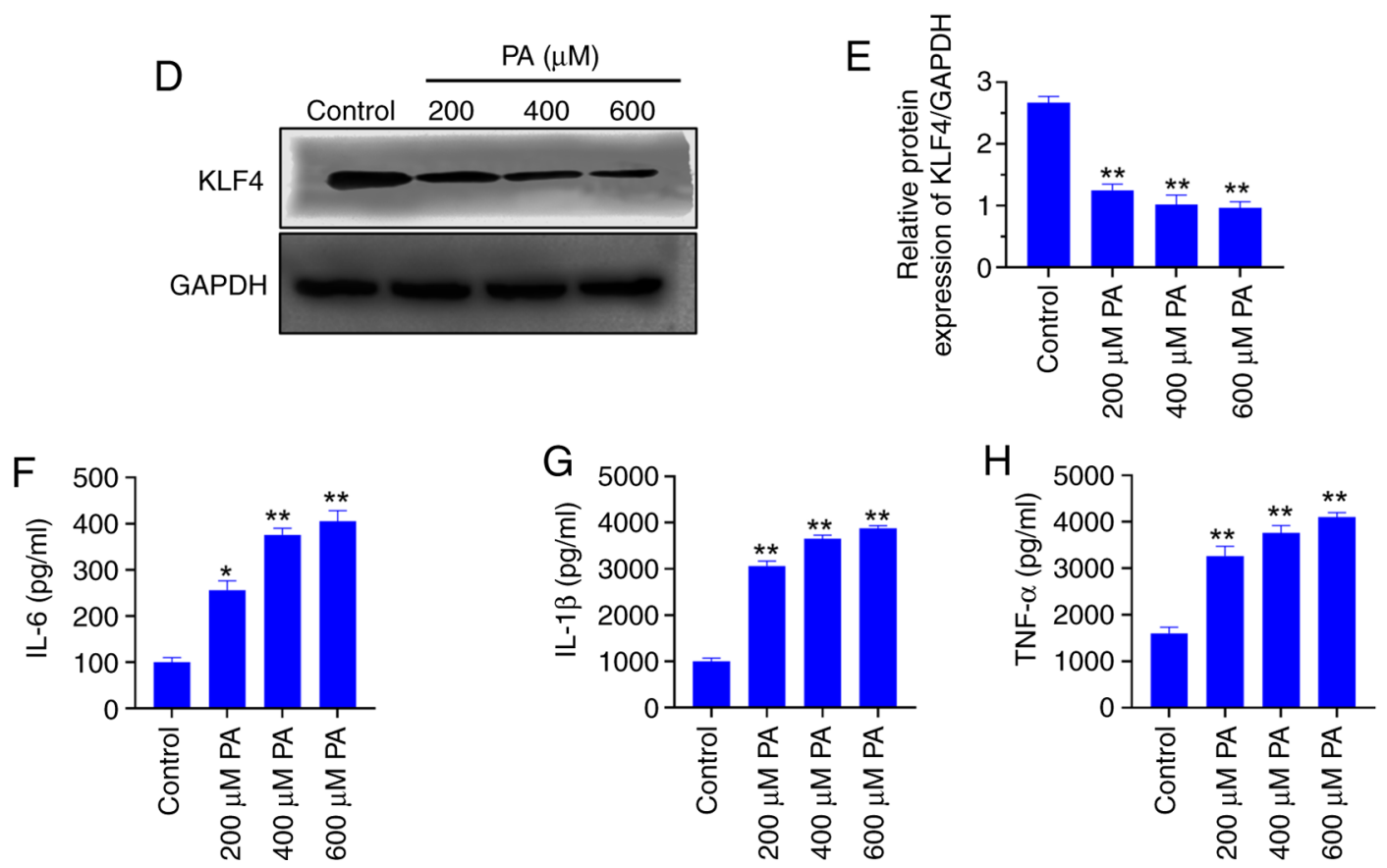

Figure 2. PA-induced insulin resistance downregulates the expression of KLF4 in macrophages. (A) 2-deoxy-2-[(7-nitro-2,1,3-benzoxadiazol-4-yl) amino]-D-glucose uptake detection. (B) Representative western blots and (C) semi-quantification of the protein expression levels of insulin resistance-related proteins. (D) Representative western blots and (E) semi-quantification of KLF4 protein expression levels. ELISA detection of the levels of (F) IL-6, (G) IL-1 $\beta$ and $(\mathrm{H})$ TNF- $\alpha$ following treatment with different concentrations of $\mathrm{PA}$. ${ }^{*} \mathrm{P}<0.05$ and ${ }^{* *} \mathrm{P}<0.01$ vs. control. IL, interleukin; INSR, insulin receptor; IRS1, insulin receptor substrate 1; KLF4, Krüppel-like factor 4; p, phosphorylated; PA, palmitic acid; TNF- $\alpha$, tumor necrosis factor $\alpha$.

At the same time, the relative protein expression level of KLF4 was significantly decreased in PA-treated cells compared with the control group $(\mathrm{P}<0.01$; Fig. $2 \mathrm{D}$ and $\mathrm{E})$. After treatment with different PA concentrations, the levels of inflammatory cytokines IL-6, IL-1 $\beta$ and TNF- $\alpha$ in the cells increased significantly compared with untreated control cells $(\mathrm{P}<0.01$; Fig. 2F-H, respectively).

PA mediates macrophage insulin resistance through Gal-3. Western blotting analysis of the peripheral blood showed that Gal-3 was significantly upregulated in T2DM patients compared with healthy individuals $(\mathrm{P}<0.05$; Fig. $3 \mathrm{~A}$ and $\mathrm{C})$. Moreover, compared with the control group, different concentrations of PA significantly increased the expression of Gal-3 in treated macrophages $(\mathrm{P}<0.01$; Fig. $3 \mathrm{~B}$ and $\mathrm{D})$. Therefore, it was speculated that Gal-3 may be involved in the regulation of insulin resistance by macrophages. Fig. 3E suggested that 100 , 400 or $600 \mu \mathrm{M}$ PA significantly increased Gal-3 expression when compared with the control group. The MTT viability assay was performed on macrophages treated with different concentrations of PA. When the PA treatment concentration was $400 \mu \mathrm{M}$, cell viability was not significantly affected compared with that in the control group ( $\mathrm{P}>0.05$; Fig. 3F). However, at $600 \mu \mathrm{M}$, cell viability decreased significantly compared with that in the control group $(\mathrm{P}<0.01)$. Taking into account the effects of different concentrations of PA on the protein and gene expression levels and cell viability of GAL-3 in macrophages, $400 \mu \mathrm{M}$ PA was selected as the appropriate treatment concentration for further experiments.

Following PA treatment, macrophages were treated with the Gal-3 inhibitor GB1107 (37 nM), and the results showed that GB1107 could significantly slow down the weakening effect of PA on the glucose uptake capacity of macrophages $(\mathrm{P}<0.01$; Fig. 4A), thereby alleviating the PA-induced insulin resistance of macrophages. In addition, after adding GB1107, the relative protein expression level of Gal-3 in PA-treated macrophages was significantly reduced, but the protein of Gal-3 was not affected (20) $(\mathrm{P}<0.01$; Fig. 4B and C). Western 

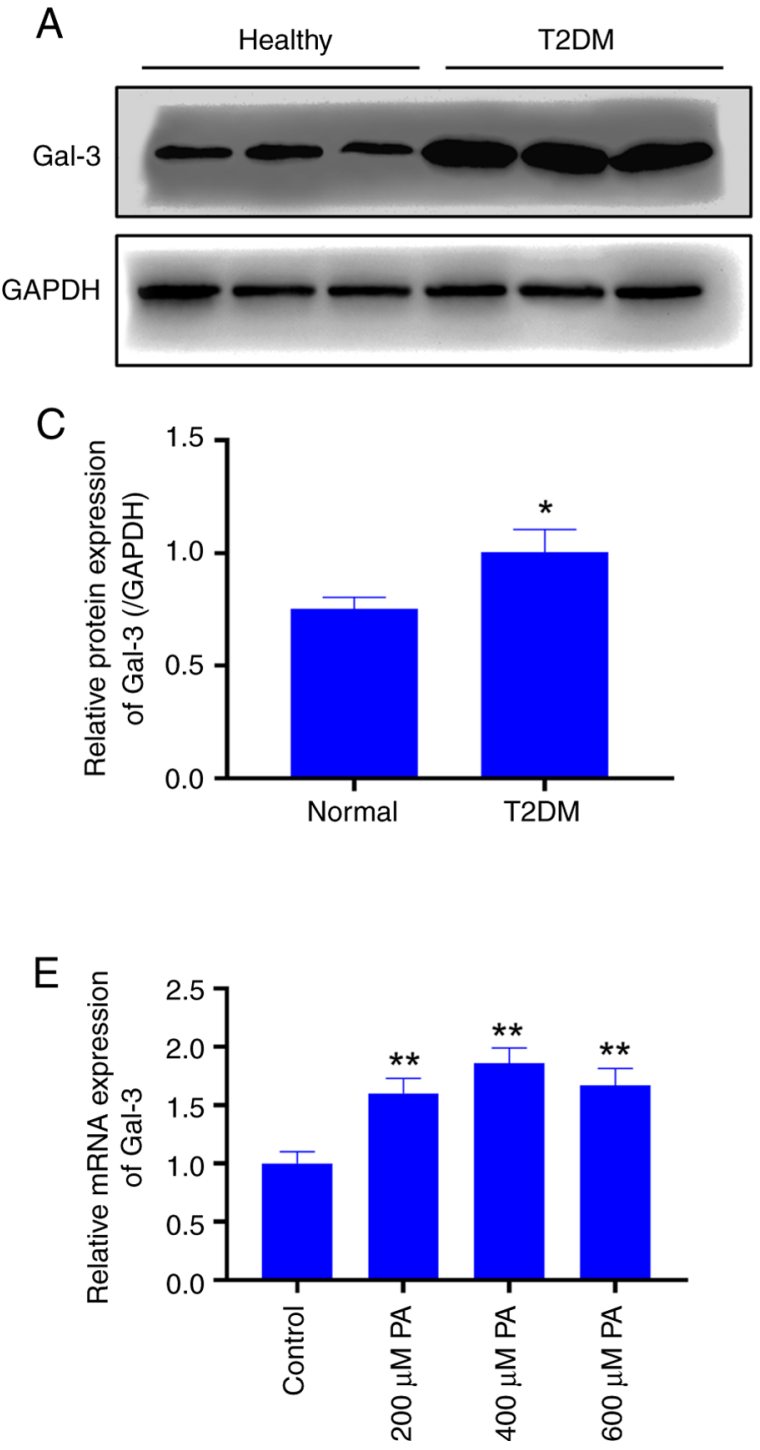
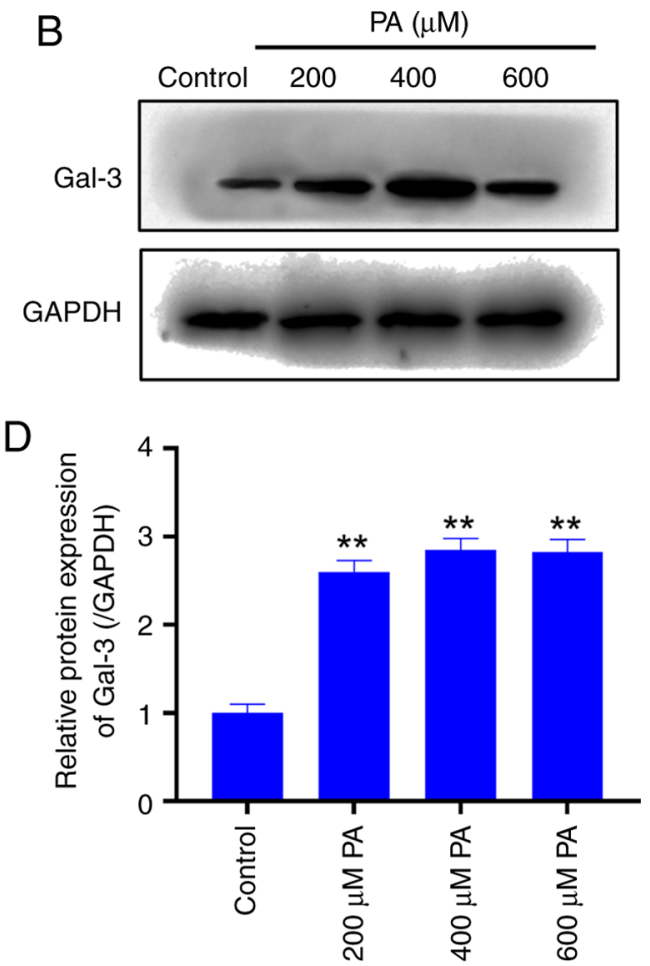

$\mathrm{F}$

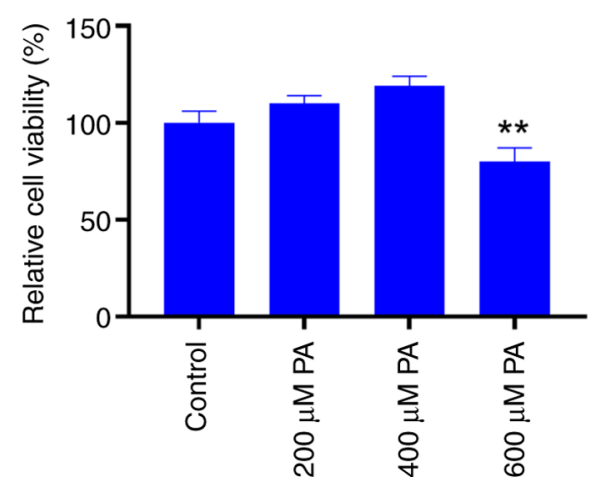

Figure 3. PA treatment promotes the expression of Gal-3. (A) Representative western blots and (B) semi-quantification of the protein expression levels of Gal-3 in different tissue samples. (C) Representative western blots and (D) semi-quantification of the protein expression levels of Gal-3 in THP-1 macrophages treated with different concentrations of PA. (E) Reverse transcription-quantitative PCR detection of Gal-3 mRNA expression levels. (F) MTT detection of the effect of different concentrations of PA on cell viability. ${ }^{*} \mathrm{P}<0.05$ and ${ }^{* *} \mathrm{P}<0.01$ vs. control. Gal-3, galectin-3; PA, palmitic acid; T2DM, type 2 diabetes mellitus.

blotting analysis and immunofluorescence demonstrated that compared with the control, Gal-3 protein was significantly down regulated in the GB1107 group (Fig. 4D), whereas Gal-3 protein expression in the PA + GB1107 group returned to the same level as in the control group. These data indicated that PA may mediate the occurrence of macrophage insulin resistance by affecting the expression of Gal-3.

$P A$ affects downstream KLF4, $p-N F-\kappa B$ and Gal-3 protein expression and mediates insulin resistance through TLR4 in macrophages. The expression levels of TLR4 protein and the downstream proteins and $\mathrm{p}-\mathrm{NF}-\kappa \mathrm{B}$, as well as Gal-3 were detected by western blot analysis (Fig. 5A). The results showed that compared with the control group, the expression of TLR4 in the PA group was significantly upregulated $(\mathrm{P}<0.01)$, and the expression of the protein KLF4 decreased (Fig. 5B). In addition, compared with the control group, the $p$-NF- $\kappa \mathrm{B}$ significantly increased $(\mathrm{P}<0.01)$ and the expression of Gal-3 was significantly upregulated $(\mathrm{P}<0.01)$ in the PA group The macrophages were cultured for $24 \mathrm{~h}$ at $5 \% \mathrm{CO}_{2}$ and $37^{\circ} \mathrm{C}$ after co-administration of PA $(400 \mu \mathrm{M})$ and the TLR4 protein inhibitor (TAK-242; $1 \mu \mathrm{M}$ ), the expression levels of KLF4 and Gal-3 protein returned to control levels, and the $\mathrm{p}-\mathrm{NF}-\kappa \mathrm{B}$ protein level was significantly inhibited $(\mathrm{P}<0.01)$. Bioinformatics analysis showed an interactive relationship between KLF4, Gal-3 and TLR4 proteins (Fig. 5C), The results suggested that $\mathrm{PA}$ may affect TLR4, $\mathrm{p}-\mathrm{NF}-\kappa \mathrm{B}$ and Gal-3 by inhibiting the expression of KLF4, thus mediating the development of insulin resistance in macrophages.

\section{Discussion}

During the development of T2DM, macrophages and other immune cells accumulate in adipose tissue. Obesity affects the biological characteristics of adipose tissue (21). However, the molecular mechanism and the key mediators 
D

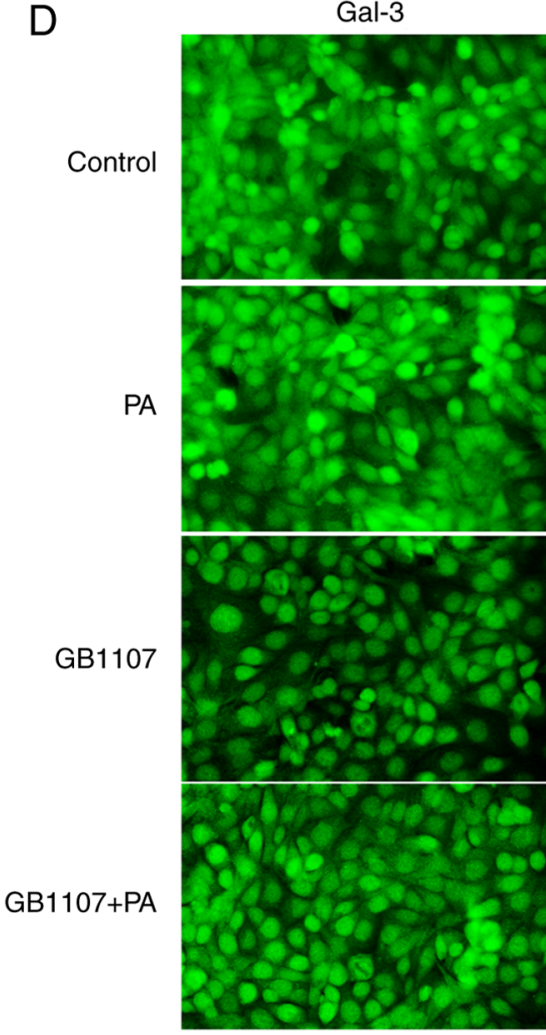

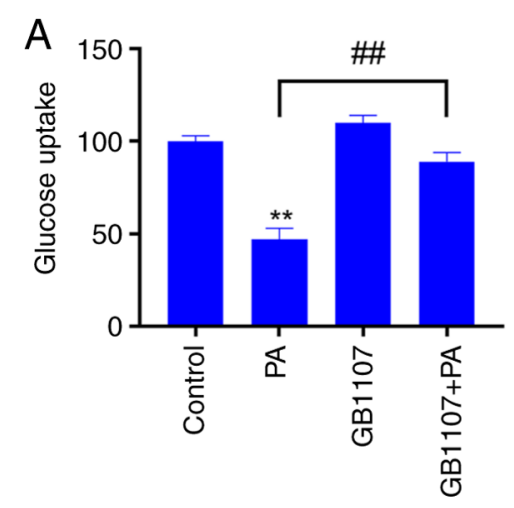

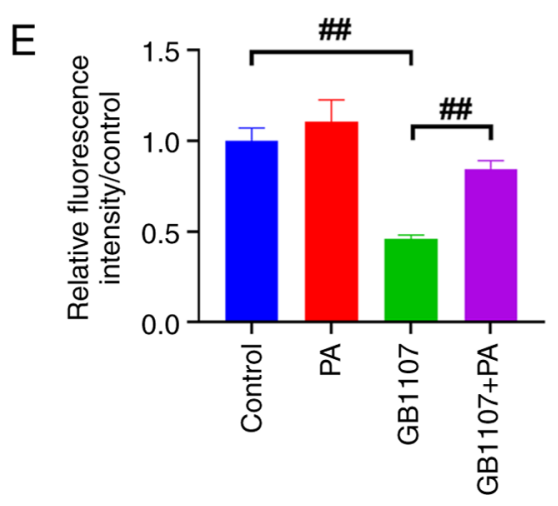

C

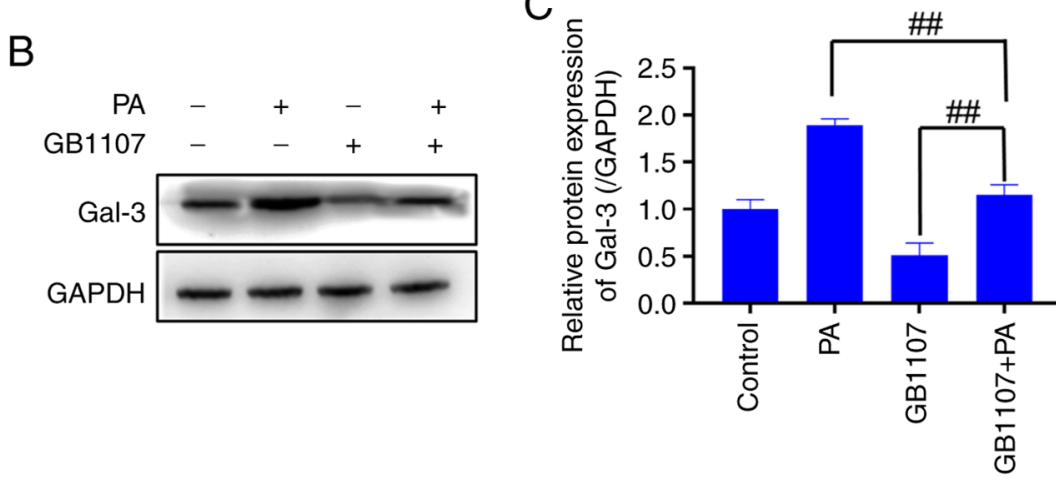

C
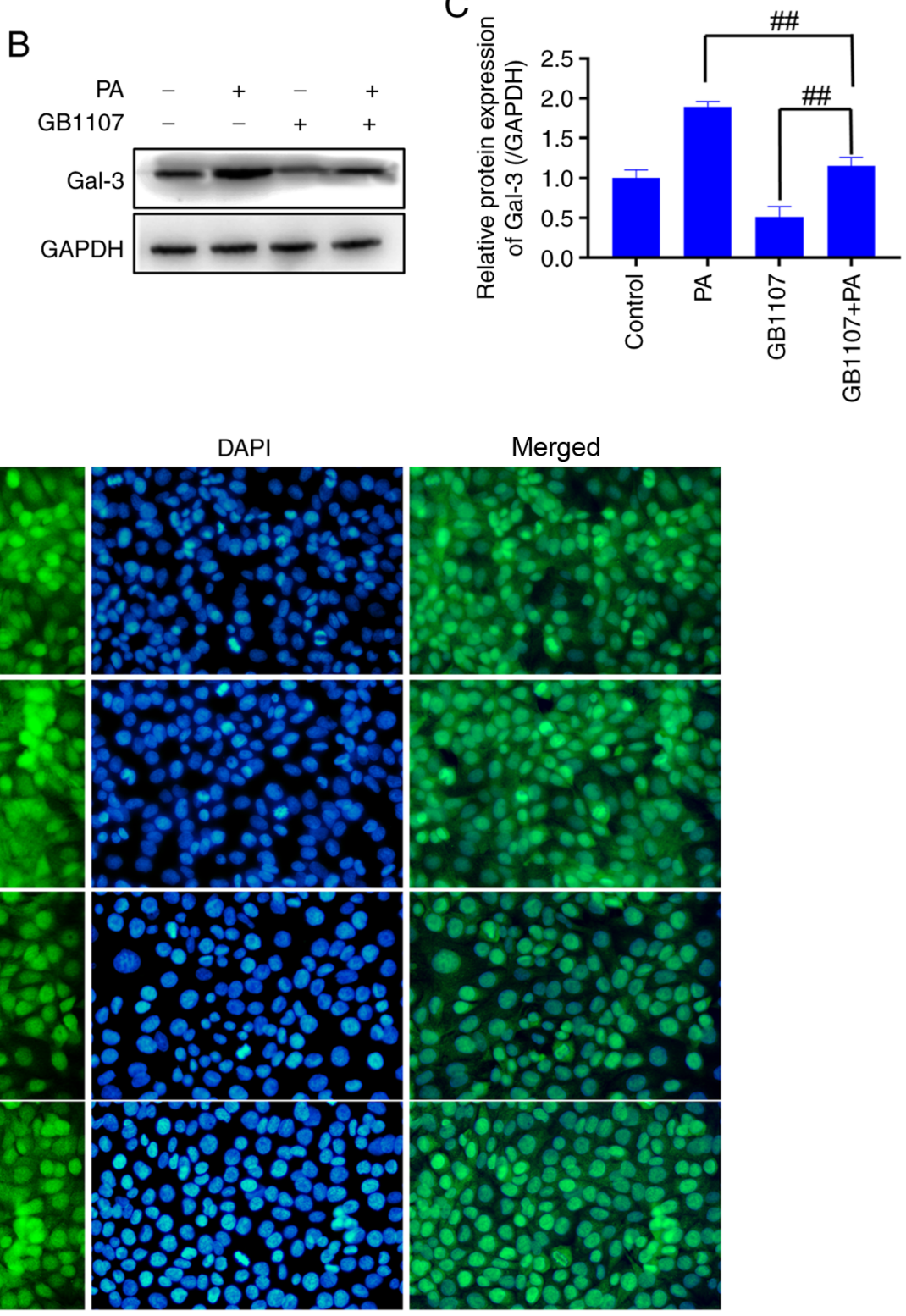

Figure 4. Gal-3 promotes insulin resistance of macrophages. Macrophages were treated with PA, the Gal-3 inhibitor GB1107 or both. (A) 2-deoxy-2[(7-nitro-2,1,3-benzoxadiazol- 4-yl) amino]-D-glucose uptake test results. (B) Representative western blots and (C) semi-quantitation of Gal-3 protein expression levels. (D) Immunofluorescence results of Gal-3. (E) Histogram shown the relative fluorescence density of Gal-3. ${ }^{* * *} \mathrm{P}<0.01$ vs. control group. ${ }^{\# \#} \mathrm{P}<0.01$ as indicated. Gal-3, galectin-3; PA, palmitic acid.

of macrophage-induced inflammation and insulin resistance in T2DM are still poorly understood. A previous study (21) indicated that the cytokines secreted by THP-1 (myeloid leukemia cell line) monocytes can communicate with a variety of cell types, such as human microvascular endothelial cells and tumor-related macrophages. Furthermore, the analysis of clinical data revealed excessive macrophage production and infiltration in patients with T2DM $(22,23)$. Therefore, 
A

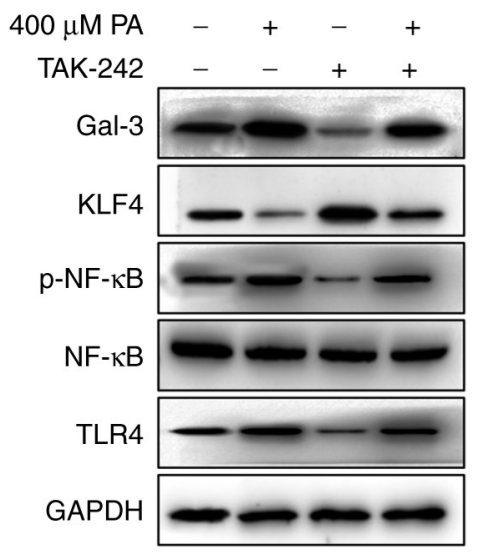

B
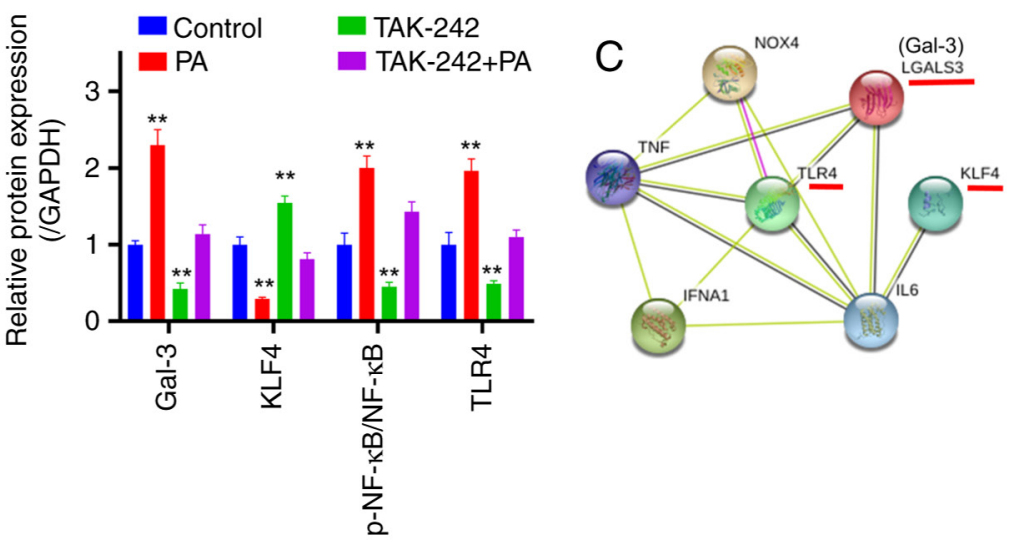

Figure 5. PA promotes the activation of the TLR4/NF- $\mathrm{B}$ pathway by downregulating KLF4 and promoting Gal-3 expression. Macrophages were treated with PA, TAK-242 and both. (A) Representative western blots and (B) semi-quantification of protein expression levels. (C) Main protein interaction map. ${ }^{* *} \mathrm{P}<0.01$ vs. control. Gal-3, galectin-3; KLF4, Krüppel-like factor 4; LGALS3, galectin-3; NF- $\kappa \mathrm{B}$, nuclear factor- $\kappa \mathrm{B}$; p, phosphorylated; PA, palmitic acid; TLR4, toll-like receptor 4; IFNA1, Interferon $\alpha$; NOX4, NADPH oxidase 4.

the present study used THP-1-derived macrophages as a cell model to test the effects of macrophage-like THP-1 cells on insulin resistance.

In the current study, THP-1 cells were induced to differentiate into macrophages. The phagocytic microsphere experiment showed that the phagocytic ability was significantly improved in PMA-induced THP-1 cells compared with untreated cells. The experimental results demonstrated that THP-cells changed from suspension cells to adherent cells after being induced by PMA, and had various shapes, clear boundaries and blunt round protrusions. This morphology was similar to that shown by Sasidhar et al (24). The phagocytosis experiment of THP-1 cells induced by PMA showed that the phagocytosis ability of THP-1 cells was significantly increased after induction, which is also an important characteristic of macrophages (25). Therefore, the success of macrophage induction was assessed from morphology and function. Furthermore, the glucose uptake rate of PA-treated macrophages decreased significantly compared with the control group. Insulin resistance was detected at the protein level, and the results were consistent with expectations. For example, INSR proteins and the ratio of p-IRS1/IRS1 (Ser1101) also showed a decrease after PA induction. A previous study also demonstrated that a decrease in p-IRS1 expression results in insulin resistance (26). Combined with the above glucose uptake experiment and the insulin-related receptor protein expression levels, it was indicated that the insulin resistance model of macrophages induced in the present study was successfully established.

Identifying the key factors that mediate the production of insulin resistance in macrophages is essential for developing effective therapeutic targets. Macrophage-derived cytokines have been considered the key regulators of the transformation of obesity-related inflammation into insulin resistance in rodents and humans. For example, Medina et al (27) reported a key role of macrophage-derived TNF- $\alpha$ in disrupting AKT-dependent insulin signaling in adipocytes by reducing AKT levels. Orliaguet et al (28) demonstrated that IL-1 $\beta$ released by macrophages affected insulin signaling and proinflammatory responses in human primary adipocytes via the insulin signaling pathway. Macrophages also impair the insulin signal transduction pathway by inhibiting the transcription of IRS1 and GLUT4, and can prompt adipocytes to activate peroxisome proliferator-activated receptor $\gamma$ and to secrete IL-6 (29). A previous study (30) demonstrated that insulin resistance is closely related to chronic inflammation and lipid metabolism. Therefore, saturated fatty acid PA, the levels of which are abnormally increased in patients with T2DM, was used in the present study to induce insulin resistance and inflammation in macrophages.

TLRs have been regarded as sensors that mediate inflammation by identifying pathogens and activating downstream signaling pathways that lead to the upregulation of inflammatory gene expression (31). Conversely, the activation of KLF4 serves a protective role in the inflammatory response (32). The activation of the TLR4-mediated inflammatory pathway in the saturated fatty acid response has been confirmed in different types of cells (33-35). Previous studies reported that the activation of KLF4 can inhibit the phosphorylation of $\mathrm{NF}-\kappa \mathrm{B}$, and that $\mathrm{NF}-\kappa \mathrm{B}$ is downstream of TLR4 (36). The degree of phosphorylation NF- $\kappa B$ has an essential relationship with inflammation $(37,38)$. It has been reported that KLF4 can induce the release of inflammatory factors in cells and serves a proinflammatory role. For example, MARIE demonstrated in the research on esophageal squamous cell carcinoma that KLF4 is an epithelial-specific mediator of inflammation, which can activate one or several proinflammatory cytokines, including TNF- $\alpha, \mathrm{C}-\mathrm{X}-\mathrm{C}$ motif chemokine 5, G-CSF and IL-1 $\alpha$ (39). Luo et al (40) revealed that over-expression of KLF4 strongly induces the production of IL-6 in human fibroblast-like synoviocytes of rheumatoid arthritis. In ischemic hemispheres, the high expression of KLF4 is always related to relatively few cerebrovascular endothelial inflammatory reactions (41). KLF4 overexpression can therefore reduce inflammation. KLF4 protein expression levels were examined in the present study. The relative protein expression levels of KLF4 decreased significantly 
in PA-treated cells compared with control cells, indicating that PA downregulated the expression of KLF4. In addition, the content of inflammatory factors also revealed that insulin-resistant macrophages were associated with increased levels of inflammatory factors, which suggested that the decrease in KLF4 expression may promote an increase in the M1 phenotype of macrophages, intensifying the inflammatory reaction. It needs further study, and no similar report has been found so far. The inflammatory response of macrophages serves an important role in its phenotype, and the presence of KLF4 serves an important role in inhibiting the inflammatory response of macrophages (42-44). These aforementioned studies indicate that KLF4 protein may serve different inflammatory roles in different cells.

Gal-3 is a lectin secreted by macrophages, which is involved in inflammation (44). The expression of Gal-3 increased significantly in patients with T2DM compared with the healthy controls. In addition, the expression of Gal-3 increased in macrophages treated with PA compared with the control group. Li et al (17) showed that the circulating Gal-3 levels in obese mice and humans were elevated; Gal-3 is a macrophage-derived factor that could cause systemic insulin resistance in the body. In addition, Gal-3 treatment inhibited the activity of insulin receptors, resulting in a decrease in insulin action in fat cells, muscle cells and liver cells in vitro, thus leading to a decrease in downstream signal transmission to the insulin action cascade (17). Therefore, in obese individuals, the increased levels of immune cell infiltration and inflammatory factor expression in adipose tissue are considered to be the cause of insulin resistance, in which Gal-3 serves an important role.

Gal-3 can induce macrophage chemotaxis in the adipose tissue of obese mice and promote the accumulation of inflammatory macrophages to mediate the inflammatory response in adipose tissue. Li et al (17) determined that in vitro use of Gal-3 directly enhanced the chemotaxis of macrophages and reduced glucose uptake by insulin-stimulated muscle cells. That study also demonstrated that Gal-3 directly bound to the IR and inhibited downstream IR signal transduction to inhibit the glucose output of mouse liver cells (17). This is consistent with the results of the current study. Compared with the control group, the expression of Gal-3 was significantly increased in PA-induced insulin-resistant macrophages. The results also showed that the addition of the Gal-3 inhibitor GB1107 could relieve the PA-induced inhibition of glucose uptake and utilization by macrophages, and that Gal-3 was closely related to insulin resistance. Further analysis of bioinformatics revealed that Gal-3 had an interactive relationship with TLR4 and KLF4. TLR4 may promote the expression of Gal-3 by activating the $\mathrm{p}-\mathrm{NF}-\kappa \mathrm{B}$ in its downstream pathway, and KLF4 reduced the effect of PA on $N F-\kappa B$. The inhibitor of TLR4 (TAK-242) was added to verify the predicted results. The results showed that TAK-242 could reduce the expression of TLR4, thereby affecting the level of $\mathrm{p}-\mathrm{NF}-\kappa \mathrm{B}$ in its downstream pathway and decreasing the expression level of Gal-3.

In summary, the current study demonstrated that PA treatment reduced the inhibitory effect on the TLR4/NF- $\kappa$ B pathway by inhibiting KLF4, thereby promoting the high expression of Gal-3 and ultimately leading to the development of insulin resistance. The findings may provide a theoretical basis for developing treatment strategies against T2DM.

\section{Acknowledgements}

Not applicable.

\section{Funding}

The present study was supported by The Medical Health Science and Technology Project of Zhejiang Provincial Health Commission (grant no. 2019KY192).

\section{Availability of data and materials}

The datasets used and/or analyzed during the current study are available from the corresponding author on reasonable request.

\section{Authors' contributions}

JL, YSM and FC designed and performed the experiments. DXX and TQZ performed the literature search, research design and manuscript editing. JL performed manuscript editing. JL and YSM confirm the authenticity of all the raw data. All authors read and approved the final manuscript.

\section{Ethics approval and consent to participate}

All protocols and the use of human peripheral blood were approved by The Affiliated Hospital of Medical School of Ningbo University (Ningbo, China; approval no. KY20190102). All subjects were provided Oral informed consent.

\section{Patient consent for publication}

Not applicable.

\section{Competing interests}

The authors declare that they have no competing interests.

\section{References}

1. Wang Y, Yan A, Li S, Liu B, Li H and Yan Y: Efficacy and safety of berberine in the treatment of type 2 diabetes with insulin resistance: Protocol for a systematic review. Medicine (Baltimore) 98: e16947, 2019

2. Nanditha A, Ma RC, Ramachandran A, Snehalatha C, Chan JC, Chia KS, Shaw JE and Zimmet PZ: Diabetes in Asia and the Pacific: Implications for the global epidemic. Diabetes Care 39: 472-485, 2016.

3. Hu C and Jia W: Diabetes in China: Epidemiology and genetic risk factors and their clinical utility in personalized medication. Diabetes 67: 3-11, 2018.

4. Wang YF, Sun MX, Xue H, Zhao WH, Yang XG, Zhu XY, Zhao L and Yang YX: Understanding the China blue paper on obesity prevention and control and policy implications and recommendations for obesity prevention and control in China. Zhonghua Yu Fang Yi Xue Za Zhi 53: 875-884, 2019 (In Chinese).

5. Qin X, Zhao Y, Gong J, Huang W, Su H, Yuan F, Fang K, Wang D, Li J, Zou X, et al: Berberine protects glomerular podocytes via inhibiting drp1-mediated mitochondrial fission and dysfunction. Theranostics 9: 1698-1713, 2019.

6. Lee YS, Kim JW, Osborne O, Oh DY, Sasik R, Schenk S, Chen A, Chung H, Murphy A, Watkins SM, et al: Increased adipocyte O2 consumption triggers HIF-1 $\alpha$, causing inflammation and insulin resistance in obesity. Cell 157: 1339-1352, 2014.

7. Siwicki M, Engblom C and Pittet MJ: Gal3 links inflammation and insulin resistance. Cell Metab 24: 655-656, 2016. 
8. Cimini FA, Barchetta I, Ciccarelli G, Leonetti F, Silecchia G, Chiappetta C, Di Cristofano C, Capoccia D, Bertoccini L, Ceccarelli V, et al: Adipose tissue remodelling in obese subjects is a determinant of presence and severity of fatty liver disease. Diabetes Metab Res Rev 37: e3358, 2021.

9. Hotamisligil GS, Shargill NS and Spiegelman BM: Adipose expression of tumor necrosis factor-alpha: Direct role in obesity-linked insulin resistance. Science 259: 87-91, 1993.

10. Nieto-Vazquez I, Fernandez-Veledo S, Krämer DK, Vila-Bedmar R, Garcia-Guerra L and Lorenzo M: Insulin resistance associated to obesity: The link TNF-alpha. Arch Physio Biochem 114: 183-194, 2008

11. Tesz GJ, Guilherme A, Guntur KV, Hubbard AC, Tang X, Chawla A and Czech MP: Tumor necrosis factor alpha (TNFalpha) stimulates Map4k4 expression through TNFalpha receptor 1 signaling to $\mathrm{c}-J u n$ and activating transcription factor 2 . J Biol Chem 282: 19302-19312, 2007.

12. Brady NJ, Chuntova P and Schwertfeger KL: Macrophages: Regulators of the inflammatory microenvironment during mammary gland development and breast cancer. Mediators Inflamm 2016: 4549676, 2016.

13. Nicholas DA, Zhang K, Hung C, Glasgow S, Aruni AW, Unternaehrer J, Payne KJ, Langridge W and De Leon M: Palmitic acid is a toll-like receptor 4 ligand that induces human dendritic cell secretion of IL-1 $\beta$. PLoS One 12: e0176793, 2017.

14. Loh K, Deng H, Fukushima A, Cai X, Boivin B, Galic S, Bruce C, Shields BJ, Skiba B, Ooms LM, et al: Reactive oxygen species enhance insulin sensitivity. Cell Metab 10: 260-272, 2009.

15. Bes-Houtmann S, Roche R, Hoareau L, Gonthier MP, Festy F, Caillens H, Gasque P, d'Hellencourt CL and Cesari M: Presence of functional TLR2 and TLR4 on human adipocytes. Histochem Cell Biol 127: 131-137, 2007.

16. Shi H, Kokoeva MV, Inouye K, Tzameli I, Yin $\mathrm{H}$ and Flier JS : TLR4 links innate immunity and fatty acid-induced insulin resistance. J Clin Invest 116: 3015-3025, 2006

17. Li P, Liu S, Lu M, Bandyopadhyay G, Oh D, Imamura T, Johnson A, Sears D, Shen Z, Cui B, et al: Hematopoietic-derived galectin-3 causes cellular and systemic insulin resistance. Cell 167: 973-984, 2016

18. Johnson A, Hou S and Li P: Inflammation and insulin resistance: New targets encourage new thinking: Galectin-3 and LTB $_{4}$ are pro-inflammatory molecules that can be targeted to restore insulin sensitivity. Bioessays 39: 10.1002, 2017.

19. Livak KJ and Schmittgen TD: Analysis of relative gene expression data using real-time quantitative PCR and the 2(-Delta Delta C(T)) method. Methods 25: 402-408, 2001.

20. Ren Z, Liang W, Sheng J, Xun C, Xu T, Cao R and Sheng W: Gal-3 is a potential biomarker for spinal cord injury and Gal-3 deficiency attenuates neuroinflammation through ROS/TXNIP/NLRP3 signaling pathway. Biosci Rep 39: BSR20192368, 2019

21. Huh JY, Park YJ, Ham M and Kim JB: Crosstalk between adipocytes and immune cells in adipose tissue inflammation and metabolic dysregulation in obesity. Mol Cells 37: 365-371, 2014.

22. Zhang M, Zhou Z, Wang J and Li S: MiR-130b promotes obesity associated adipose tissue inflammation and insulin resistance in diabetes mice through alleviating M2 macrophage polarization via repression of PPAR- $\gamma$. Immunol Lett 180: 1-8, 2016.

23. Odegaard JI and Chawla A: Mechanisms of macrophage activation in obesity-induced insulin resistance. Nat Clin Pract Endocrinol Metab 4: 619-626, 2008.

24. Sasidhar MV, Chevooru SK, Eickelberg O, Hartung HP and Neuhaus O: Downregulation of monocytic differentiation via modulation of CD147 by 3-hydroxy-3-methylglutaryl coenzyme A reductase inhibitors. PLoS One 12: e0189701, 2017.

25. Kapellos TS, Taylor L, Lee H, Cowley SA, James WS, Iqbal AJ and Greaves DR: A novel real time imaging platform to quantify macrophage phagocytosis. Biochem Pharmacol 116: 107-119, 2016.

26. Talbot NA, Wheeler-Jones CP and Cleasby ME: Palmitoleic acid prevents palmitic acid-induced macrophage activation and consequent p38 MAPK-mediated skeletal muscle insulin resistance. Mol Cell Endocrinol 393: 129-142, 2014.
27. Medina EA, Morris IR and Berton MT: Phosphatidylinositol 3-kinase activation attenuates the TLR2-mediated macrophage proinflammatory cytokine response to Francisella tularensis live vaccine strain. J Immunol 185: 7562-7572, 2010.

28. Orliaguet L, Dalmas E, Drareni K, Venteclef N and Alzaid F: Mechanisms of macrophage polarization in insulin signaling and sensitivity. Front Endocrinol (Lausanne) 11: 62, 2020.

29. Cipolletta D, Feuerer M, Li A, Kamei N, Lee J, Shoelson SE, Benoist C and Mathis D: PPAR- $\gamma$ is a major driver of the accumulation and phenotype of adipose tissue treg cells. Nature 486: 549-553, 2012.

30. Chen L, Chen R, Wang H and Liang F: Mechanisms linking inflammation to insulin resistance. Int J Endocrinol 2015: 508409, 2015.

31. Zhu Y, Deng J, Nan ML, Zhang J, Okekunle A, Li JY, Yu XQ and Wang PH: The interplay between pattern recognition receptors and autophagy in inflammation. Adv Exp Med Biol 1209: 79-108, 2019.

32. Jin L, Ye H, Pan M, Chen Y, Ye B, Zheng Y, Huang W, Pan S, Shi $Z$ and Zhang J: Kruppel-like factor 4 improves obesity-related nephropathy through increasing mitochondrial biogenesis and activities. J Cell Mol Med 24: 1200-1207, 2020.

33. Wang Z, Liu D, Wang F, Liu S, Zhao S, Ling EA and Hao A: Saturated fatty acids activate microglia via toll-like receptor 4/NF- $\kappa B$ signalling. Br J Nutr 107: 229-241, 2012.

34. Tian H, Liu C, Zou X, Wu W, Zhang C and Yuan D: miRNA-194 regulates palmitic acid-induced toll-like receptor 4 inflammatory responses in THP-1 cells. Nutrients 7: 3483-3496, 2015.

35. Xu D, Liang J, Cui M, Zhang L, Ren S, Zheng W, Dong X and Zhang B: Saturated fatty acids activate the inflammatory signalling pathway in schwann cells: Implication in sciatic nerve injury. Scand J Immunol 92: e12896, 2020.

36. Kaushik DK, Mukhopadhyay R, Kumawat KL, Gupta M and Basu A: Therapeutic targeting of krüppel-like factor 4 abrogates microglial activation. J Neuroinflammation 9: 57, 2012.

37. Allen KL, Hamik A, Jain MK and McCrae KR: Endothelial cell activation by antiphospholipid antibodies is modulated by kruppel-like transcription factors. Blood 117: 6383-6391, 2011.

38. Huang $\mathrm{H}$, Wei L, Qin T, Yang N, Li Z and Xu Z: Circular RNA ciRS-7 triggers the migration and invasion of esophageal squamous cell carcinoma via miR-7/KLF4 and NF- $\kappa \mathrm{B}$ signals. Cancer Biol Ther 20: 73-80, 2019.

39. Tetreault MP, Wang ML, Yang Y, Travis J, Yu QC, Klein-Szanto AJ and Katz JP: Klf4 overexpression activates epithelial cytokines and inflammation-mediated esophageal squamous cell cancer in mice. Gastroenterology 139: 2124-2134, 2010

40. Luo X, Chen J, Ruan J, Chen Y, Mo X, Xie J and Lv G: Krüppel-like factor 4 is a regulator of proinflammatory signaling in fibroblast-like synoviocytes through increased IL-6 expression. Mediators Inflamm 2016: 1062586, 2016.

41. Zhang X, Wang L, Han Z, Dong J, Pang D, Fu Y and Li L: KLF4 alleviates cerebral vascular injury by ameliorating vascular endothelial inflammation and regulating tight junction protein expression following ischemic stroke. J Neuroinflammation 17: 107, 2020.

42. Wen Y, Lu X, Ren J, Privratsky JR, Yang B, Rudemiller NP, Zhang J, Griffiths R, Jain MK, Nedospasov SA, et al: KLF4 in macrophages attenuates TNF $\alpha$-mediated kidney injury and fibrosis. J Am Soc Nephrol 30: 1925-1938, 2019.

43. Liao X, Sharma N, Kapadia F, Zhou G, Lu Y, Hong H, Paruchuri K, Mahabeleshwar GH, Dalmas E, Venteclef N, et al: Krüppel-like factor 4 regulates macrophage polarization. J Clin Invest 121: 2736-2749, 2011.

44. Henderson NC and Sethi T: The regulation of inflammation by galectin-3. Immunol Rev 230: 160-171, 2009.

This work is licensed under a Creative Commons Attribution-NonCommercial-NoDerivatives 4.0 International (CC BY-NC-ND 4.0) License. 